\title{
Ingestible Wireless Capsule Technology: A Review of Development and Future Indication
}

\author{
M. R. Basar, ${ }^{1}$ F. Malek, ${ }^{2}$ Khairudi M. Juni, ${ }^{3}$ M. Shaharom Idris, ${ }^{3}$ and M. Iskandar M. Saleh ${ }^{3}$ \\ ${ }^{1}$ School of Computer and Communication Engineering, Universiti Malaysia Perlis (UniMAP), 02000 Kuala Perlis, Perlis, Malaysia \\ ${ }^{2}$ School of Electrical Systems Engineering, Universiti Malaysia Perlis (UniMAP), 02600 Arau, Perlis, Malaysia \\ ${ }^{3}$ Electrical Engineering Department, Politeknik Tuanku Syed Sirajuddin (PTSS), 02600 Arau, Perlis, Malaysia
}

Correspondence should be addressed to M. R. Basar, rubel24434@yahoo.com

Received 27 July 2012; Accepted 3 December 2012

Academic Editor: Ahmed A. Kishk

Copyright (C) 2012 M. R. Basar et al. This is an open access article distributed under the Creative Commons Attribution License, which permits unrestricted use, distribution, and reproduction in any medium, provided the original work is properly cited.

\begin{abstract}
Ingestible wireless capsule endoscopy (WCE) is the one and only painless, effective, novel, diagnostic technology for inspecting the entire gastrointestinal (GI) tract for various diseases, such as obscure gastrointestinal bleeding (OGIB), tumors, cancer, Crohn's disease, and celiac disease. Since the development of this technology, several companies have made remarkable improvements in their clinical products, but there are still some limitations that relate to the use of conventional wired endoscopy. Some of the major limitations that currently impede its wider application include its inability to repeat the view of critical areas, working time constraints, and poor image resolution. Many research groups currently are working on ways to solve these limitations. Presently, developing the ability to control the movement of the capsule, increasing its image transmission speed, and obtaining high-quality images are the main issues in the research area. A complex capsule with some therapeutic tools for the treatment of diseases of the GI tract also is at the beginning of development for the next generation of an active medical robot. In this paper, we report the status of several activities related to WCE, including improvement of capsule technology, research progress, technical challenges, and key indicators concerning the next-generation, active, medical robot.
\end{abstract}

\section{Introduction}

Angiography, ultrasonography, X-radiography, computer tomography (CT), and magnetic resonance imaging (MRI) are conventional, indirect technologies for examining GI tract diseases, such as obscure gastrointestinal bleeding (OGIB), tumors, cancer, Crohn's disease, and celiac disease. Regrettably, these technologies have low diagnostic yields because of their inability to show the wall of the GI tract. Another typical technology, probe endoscopy, is used for diagnosing diseases of the GI tract, but, in addition to being painful and creating discomfort, it is incapable of reaching some critical locations in the GI tract.

In 2000, Iddan et al. first developed a wireless video capsule endoscopy system $[1,2]$ that patients could swallow, but its development has been started since long ago. The first attempt at endoscopic examination was conducted in 1806 by Philipp Bozzini. The effective visualization of the GI tract began with the development of typical wire endoscopy, such as rigid-wire endoscopy, flexible endoscopy, and fiberoptic push endoscopy. William Beaumont, an army surgeon, first introduced an endoscope into a human in 1822 and, 30 years later, the effective, rigid-wire endoscope was developed [3-5]. The use of the rigid-wire endoscope was limited to the curly, upper anatomical area of the digestive path. The flexible endoscope provided a unique solution for that problem, and it led to the development of the fiberoptic endoscope in 1957 [6-8]. However, in addition to the pain and discomfort they caused, the main problem associated with these enteroscopes was their limited insertion into the GI tract, only reaching as far as the upper portion of the small bowel [9].

In the 1950s, the first wireless capsule was developed, but it had very limited capabilities in that it could only measure a few physiological parameters of the GI tract, such as temperature, $\mathrm{pH}$, and pressure. This device was known as an endoradiosonder or "radio pill" (sometimes referred to as "gutnick"). The wireless capsule of this 
period was a tiny, swallowable transmitter either with $\mathrm{pH}$, pressure, or temperature sensors that created variations in the L-C oscillator's output frequency of a tiny transmitter according to the sensor's output [10-13]. Heidelberg Medical Inc. in Germany first developed the $\mathrm{pH}$ parameter capsule system. This capsule was $15.4 \mathrm{~mm}$ long and $7.1 \mathrm{~mm}$ in diameter with a battery that had a six-hour lifetime, a radio frequency transmitter, and an electrode, and it was used for diagnosing hypochlorhydria and achlorhydria [14]. Later, the American SmartPill Company developed a medical product, known as SmartPill, which combined those three sensors for measuring pressure, temperature, and $\mathrm{pH}$. The SmartPill is approved by the Food and Drug Administration (FDA). The SmartPill system consisted of four subsystems, that is, (1) the ingestible capsule itself, containing pressure, temperature, and $\mathrm{pH}$ sensors, along with a battery and a tiny radio transmitter (with a frequency of $434 \mathrm{MHz}$ ); (2) a portable receiver inside a jacket for receiving sensor data; (3) MotiliGI monitoring software; and (4) a receiver docking station [15].

In 1981, Iddan first developed the concept of wireless video capsule endoscopy to see the wall of the GI tract painlessly, but the state of the development of the required technology deterred the realization of this concept. Fourteen years later, Swain et al. (1997) developed several prototypes of a capsule endoscopy system and successfully conducted a vast number of experiments on postmortem and live pigs [16]. In those prototypes, they used a miniature chargecoupled device (CCD) camera, a video processor, a $10 \mathrm{~mW}$ microwave transmitter with a $1.5 \mathrm{~cm}$ dipole antenna, a light source, and a battery. In 2000, the introduction of the lowpower, complementary, metal oxide semiconductor-based (CMOS-based) image sensor and ASIC made the video capsule possible [1]. Given Imaging, Ltd. (Yoqneam, Israel) announced the first clinical product, M2A (mouth to anus), for examination of the small bowel, and the product was approved by the US FDA in the same year [17]. Due to the dissimilarities of different areas of the GI tract, Given Imaging, Ltd. launched its esophagus-specific and colonspecific capsules, that is, PillCam ESo and PillCam Colon, respectively. In addition to Given Imaging Ltd., Jinshan (China), Olympus (Japan), and IntroMedic (Korea) made significant improvements in the performances of their own endoscopic capsules. Even so, all of the present capsules that are used move through the GI tract by the natural motility of the tract itself. There is no control of the capsules' movements or camera orientation, which limits the accuracy of medical diagnoses. Along with this, the poor image resolution and low frame rate confine the wider application of the capsules for sensitive detection. Overcoming these limitations and developing the next generation of such capsules with enhanced functionality and control is the objective of present research in this area. The aim of this paper mainly was to indicate promising ways for developing active medical robots along with an overview of present capsule endoscopy systems, including their limitations and the progress of related research.

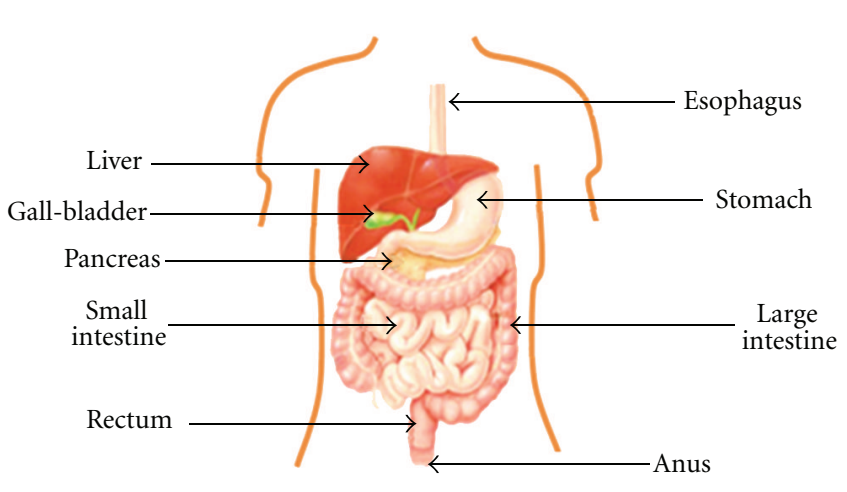

Figure 1: Architecture of the human GI tract [18].

\section{Human GI Tract and Capsule System}

Knowledge of the architecture of the human GI tract or digestive tract is very important for the appropriate development of wireless capsule endoscopy systems. Figure 1 [18] shows that the human gastrointestinal tract consists of four main parts, that is, the esophagus, stomach, small intestine/bowel, and large intestine or colon. The total length of an adult human's digestive tract is approximately eight meters, with the small intestine, which is approximately $3-4 \mathrm{~cm}$ in diameter, comprising $5-6 \mathrm{~m}$ of the total length $[19,20]$. Because of its complex, curvy structure, the small intestine is the most convoluted part of the digestive path, and conventional endoscopes are unable to pass through it $[8,21]$. Conversely, the esophagus is a straight tube that is $25-30 \mathrm{~cm}$ in length, and a typical, rigid, wire endoscope can pass through it easily. The third part of the GI tract is the colon, which is about $1.5 \mathrm{~m}$ long and has a diameter of about $6.5 \mathrm{~cm}$. Its larger diameter increases the likelihood that the small, bowel-specific capsule could fail to detect potential problems. Due to the anatomical disparities between the different sections of GI tract, developing the capsule arises the diverse complexity, especially for the active capsule's control mechanisms.

The motion of endoscopic capsule systems that are currently being used cannot be actively controlled as they pass through the GI tract. Rather, it passively moves based on the peristaltic motion of the digestive path. This passive capsule system contains three key parts (Figure 2), that is, the ingestible capsule, a portable image-recording belt or jacket, and workstation computer with image processing software [2, 22]. Some recent capsule systems, such as PillCam Colon 2, use an additional real-time image display to perceive the progress of examination. The endoscopic capsule is an electronic pill of swallowable size that captures images during its transit through the GI tract, processes the images, and transmits the data to the data-receiving unit through the digital, radiofrequency channel [23, 24]. Figure 2(a) depicts the inner architecture of the capsule, showing the CMOS image sensor with a light-emitting diode and lens for capturing images while passing through the GI tract, the ASIC transceiver with an antenna for transmitting 


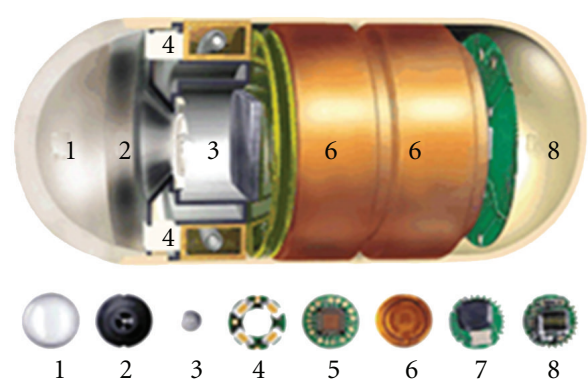

(a)

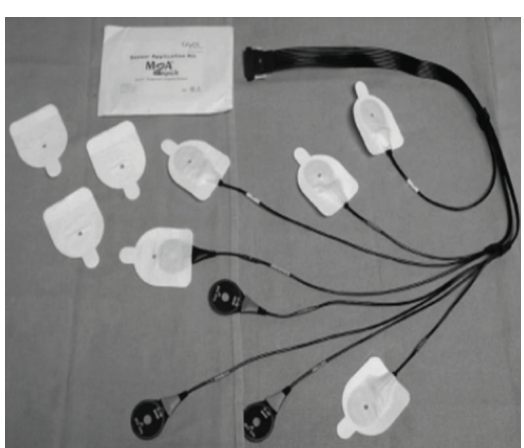

(b)

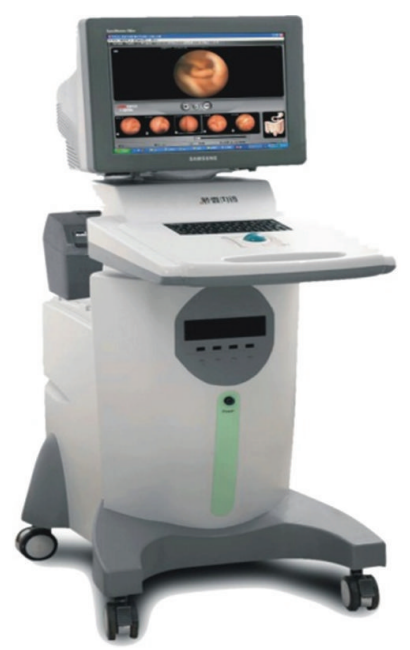

(c)

FIGURE 2: (a) Endoscopic capsule—1, Optical dome; 2, lens holder; 3, lens; 4, lEDs; 5, COMS imager; 6, battery; 7, ASIC transceiver; 8, antenna [25]. (b) Image recording unit [22]. (c) Workstation [26].

captured image data to the receiving unit, and two batteries that provide power [25].

In the image-recording subsystem, almost every system uses eight body leads/antennas (except three leads in oesophageal operation and 14 leads in the OMOM capsule system). The body leads are attached to the abdomen and the chest according to the guidelines. These body leads allow the detection of the position of the capsule and continuously receive the signals that indicate the different positions of the capsule [28]. Figure 3 shows the setup of the body leads on the patient's body [27]. In the workstation computer, powerful software is used to process the recorded image. In the software, an advanced algorithm is used to determine the location of the capsule based on the location of the lead, receiving the strongest signal. The algorithm also can detect different color pixels that distinguish the disorders of GI tract [29].

\section{Present Endoscopic Capsule}

Since the development of the endoscopic capsule, some companies have introduced the capsule using different names for use in medical diagnoses for three different areas of the GI tract, that is, the esophagus, the small intestine, and the colon. The first clinical capsule developed by Given Imaging, Ltd. for small bowel diagnoses was called the M2A (mouth to anus) capsule, which later became known as PillCam SB [30, 31] (Figure 4(a)). The inadequate view angle of PillCam SB precludes a highly sensitive disease detection. The second generation, small-bowel capsule, PillCam SB 2, was developed to overcome the limitations of the first generation, small-bowel capsule. The main difference between PillCam SB and PillCam SB 2 is a three-lens system that is used in PillCam SB 2, powerfully increasing the view angle from $140^{\circ}$ to $156^{\circ}$, which enables the system to view nearly twice as much area on the surface of the intestine [33]. In addition, it uses four LEDs instead of six, and it has an automatic light exposure sensor that increases the effective life of the battery. Also, in 2010, Given Imaging, Ltd. marketed another capsule system, PillCam SB 2 Ex with manually guided GI scope [34]. PillCam SB 2 Ex was specially designed for patients who have slow anatomical motion, because its power supply can last for $12 \mathrm{~h}$ during the procedure. The Given Imaging, Ltd. also introduced oesophageal and colon-specific capsules PillCam Eso (Figure 4(b)) $[35,36]$ and PillCam Colon (Figure 4(c)) $[38,39]$ which can capture images from both ends at higher frame rate. Likewise PillCam SB 2 the second generation 


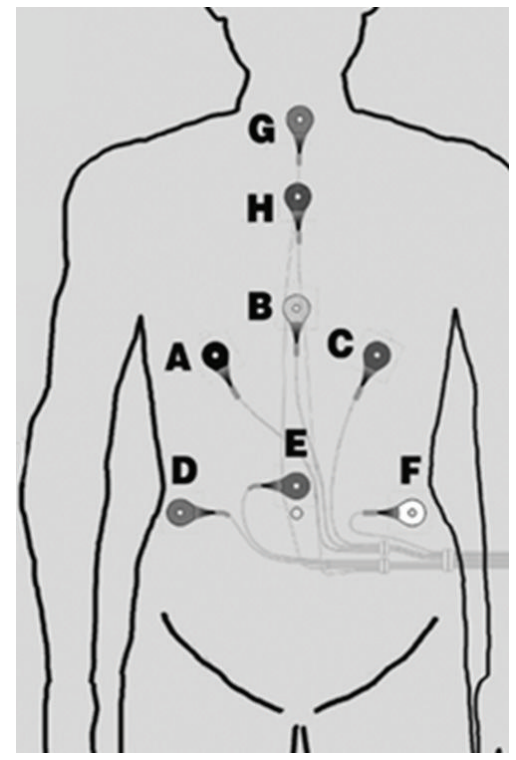

A Intersection of right 7 th intercostal space and right midclavicular line

(B) Xiphoid process

C Intersection of left 7th intercostal space and left midclavicular line

D Right lumbar region at umbilical level

E Above umbilicus (navel)

F Left lumbar region at umbilical level

(G)

(H)

Figure 3: Common setup of antenna leads on the patient's body [27].

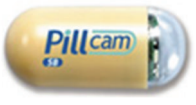

(a)

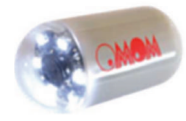

(d)

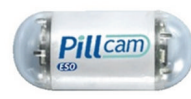

(b)

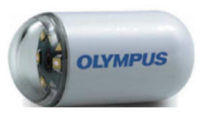

(e)

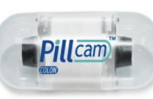

(c)

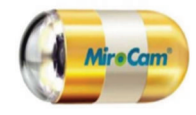

(f)
Figure 4: Present clinical capsules: (a) PillCam SB; (b) PillCam Eso; (c) PillCam Colon; [31] (d) OMOM [26]; (e) Olympus [44]; (f) MiroCam [47].

oesophageal and colon-specific capsule PillCam ESO 2 [37] and PillCam Colon 2 [40-42] also have been developed.

Some other companies like Jinshan Science and Technology, Olympus Medical System Corp., and Intro-Medic Co.,
Ltd. have contributed to improve the performance of smallbowel-specific capsule by developing their own product OMOM (Figure 4(d)) [26], Endo Capsule (Figure 4(e)) [44], and MiroCam (Figure 4(f)) [47], respectively. The OMOM capsule, which is also approved by the State FDA of the People's Republic of China, minimized the cost up to $\$ 235$, which is half of the cost of PillCam SB. On the other hand, the image resolution has been boosted up to 1920 $\times 1080$ pixels by using charge-coupled device (CCD) in Endo Capsule system. Rather than using a conventional radiofrequency channel a novel communication technology is used in MiroCam capsule. In this novel communication system (first introduced by Kim et al.), the human body is used as a communication channel for transmitting the data from inside to outside of the body [50]. MiroCam used Kim's system with the human body as the transmission medium. In this system, the baseband electrical signal was transmitted directly through the body (in a frequency range from 1 to $3 \mathrm{MHz}$ ) without any modulation that reduces the power and 


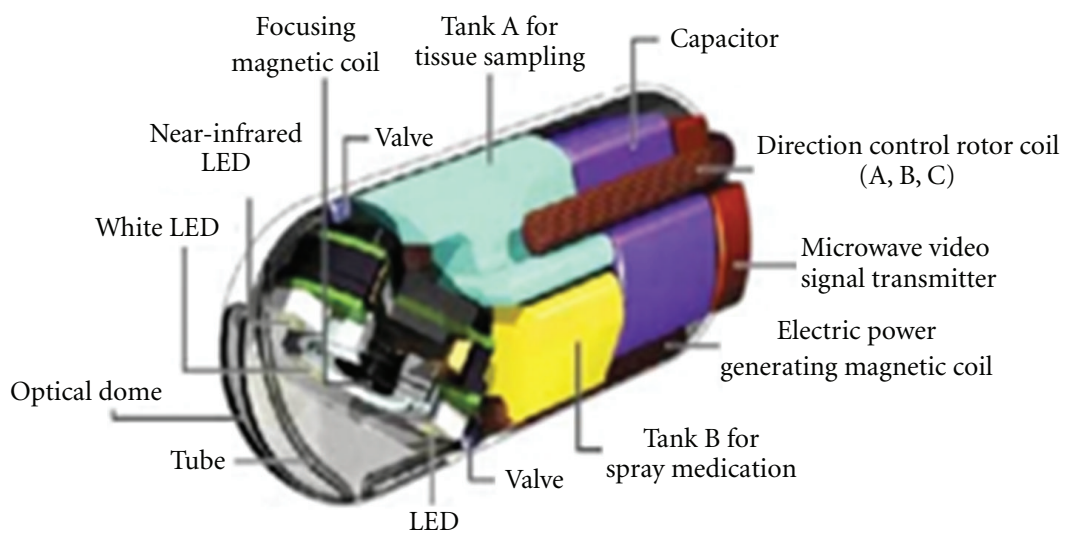

(a)

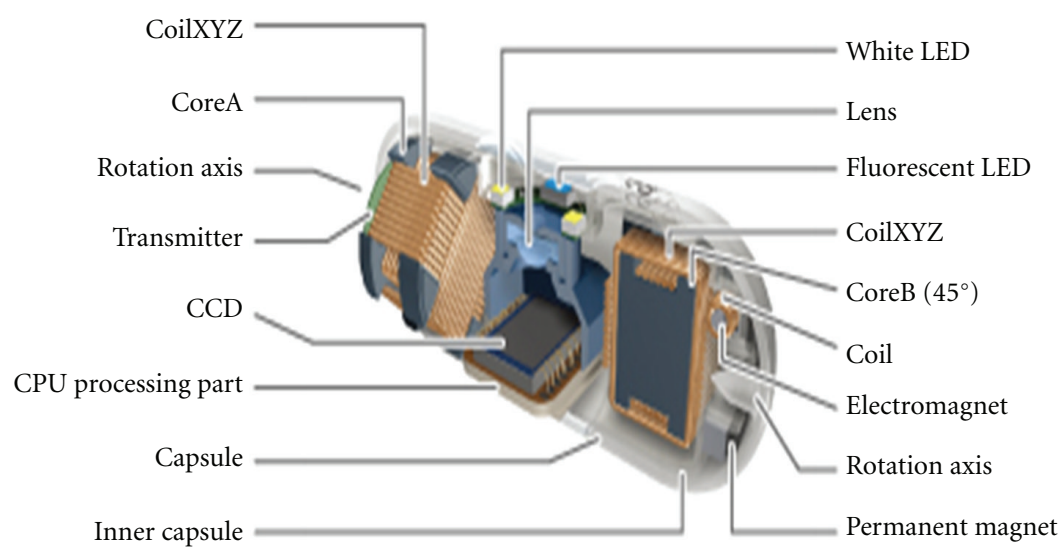

(b)

FIgURE 5: Architecture of the (a) Norika and (b) Sayaka capsule [49].

area consumption by the chip by elimination of the RF parts, such as the oscillator, modulator, and antenna.

Unlike using battery, the wireless power transmitter (WPT) technique is used by RF system Lab, Japan and developed Norika (Figure 5(a)) and Sayaka (Figure 5(b)) capsule system. Because of the intelligent camera placing, the camera view angle of these capsule boomed excellently $[24,49]$. Table 1 shows the specification of existing capsule systems.

\section{Limitation of Present Capsules}

Compared to push endoscopy, capsule endoscopy is superior in identifying abnormalities in the GI tract and in visualizing the entire length of the small intestine [51, 52]. Even so, present capsule endoscopes do not provide high image resolution and frame rates. Although the limited power is an issue, a highly efficient transceiver chip can boost the data rate with the optimized power. The most concerning limitation is the limited control of the movement of the capsules. The movement of present capsules depend on the natural transit of the bowel, which makes the system incapable of repeated examination of the same area, and the asymmetrical bowel transit (slow or fast) increases the likelihood important information chance not to be detected [53]. In addition, all of the capsules are powered by two coin-cell batteries, and, if transit is too slow for any reason, the batteries may be depleted before the examination is completed [54].

\section{Research Progress for Next-Generation Capsules}

The current research on WCE is focused on the development of miniaturized, multifunctional, medical robots that can overcome the limitations of the current capsule endoscopes. In this regard, research to develop low power, high data rate, mixedmode ASIC, microactuation system, and miniaturized proficient power source is considered to be vitally important for the design and implementation of next-generation endoscopes. In the next-generation capsules, the incorporation of mini-surgical tools and artificial intelligence of the capsules is anticipated, but, due to the technical challenges, extensive research in these areas has not been initiated. However, many research groups throughout the world are working in private research institutes and university laboratories on the different sections of such capsules. In this section, some potential research outcomes are discussed in three subsections that 
TABLE 1: Specification of current wireless endoscopic capsules [26, 28, 30-49].

\begin{tabular}{|c|c|c|c|c|c|c|c|c|c|}
\hline By & Model & $\begin{array}{c}\text { Size }(L \times D) \\
\text { in } \mathrm{mm}\end{array}$ & $\begin{array}{c}\text { Image } \\
\text { resolution }\end{array}$ & $\begin{array}{l}\text { Fame } \\
\text { rate }\end{array}$ & $\begin{array}{l}\text { View } \\
\text { angle }\end{array}$ & $\begin{array}{l}\text { Life } \\
\text { time }\end{array}$ & $\begin{array}{l}\text { Image } \\
\text { display }\end{array}$ & Weight & Approved by \\
\hline \multirow{6}{*}{ Given imaging } & PillCam SB & $26 \times 11$ & $256 \times 256$ & 2 & $140^{\circ}$ & $6-8 \mathrm{~h}$ & Offline & $3.7 \mathrm{~g}$ & FDA, 2001 \\
\hline & PillCam SB 2 & $26 \times 11$ & $256 \times 256$ & 2 & $156^{\circ}$ & $8 \mathrm{~h}$ & Offline & $3.7 \mathrm{~g}$ & FDA, 2007 \\
\hline & PillCam ESO & $26 \times 11$ & $256 \times 256$ & $2 \times 7$ & $140^{\circ}$ & $20 \mathrm{~min}$ & Offline & $3.7 \mathrm{~g}$ & FDA, 2004 \\
\hline & PillCam ESO 2 & $26 \times 11$ & $256 \times 256$ & $2 \times 9$ & $169^{\circ}$ & $20 \mathrm{~min}$ & Offline & $3.7 \mathrm{~g}$ & FDA, 2007 \\
\hline & PillCam Colon & $31 \times 11$ & $256 \times 256$ & $2 \times 2$ & $156^{\circ}$ & $10 \mathrm{~h}$ & Offline & $2.9 \mathrm{~g}$ & CE, 2006 \\
\hline & PillCam Colon 2 & $31.5 \times 11.6$ & $256 \times 256$ & $4-35$ & $172^{\circ}$ & $10 \mathrm{~h}$ & Real time & N/A & N/A \\
\hline Jinshan & OMOM & $27.9 \times 13$ & $640 \times 480$ & 2 & $140^{\circ}$ & $7-9 \mathrm{~h}$ & Real time & $6 \mathrm{~g}$ & CE, 2007 \\
\hline Intromedic & MiroCam & $24 \times 10.8$ & $320 \times 320$ & 3 & $150^{\circ}$ & $10-12 \mathrm{~h}$ & Offline & $3.3 \mathrm{~g}$ & CE, 2007 \\
\hline Olympus & EndoCapsule & $26 \times 11$ & $1920 \times 1080$ & 2 & $145^{\circ}$ & $8-10 \mathrm{~h}$ & Real time & $3.8 \mathrm{~g}$ & FDA, 2007 \\
\hline \multirow{2}{*}{ RF system Lab. } & Norika & $23 \times 9$ & 410000 & 30 & N/A & WPT & Offline & N/A & N/A \\
\hline & Sayaka & $23 \times 9$ & 410000 & 30 & $360^{\circ}$ & WPT & Offline & N/A & N/A \\
\hline
\end{tabular}

address ASIC chip designing, capsule actuation system, and miniaturized power sources.

5.1. ASIC Chip Design. In wireless endoscopic capsules, the ASIC is responsible for processing and transmitting the image data through the RF channel as well as receiving and acting on the command signals. Superior optimization in ASIC design can reduce the power consumption of the capsules and increase the number of image frames acquired per second. The higher level of integration in ASIC compresses the chip area, facilitating the installation of the actuation system and additional functions in the capsule. The first clinical capsule was launched with a $2.7 \mathrm{Mbps}, 434 \mathrm{MHz}$ radio transmitter chip with power consumption $5.2 \mathrm{~mW}$. This chip was designed specially by Zarlink Semiconductor, Inc. (Ottawa, Canada). From its inception to the present time, remarkable progress has been reported at the research level for the ASIC chip.

A low-power, near-field transmitter for capsule endoscopy was developed by Thoné et al. They used $144 \mathrm{MHz}$ carrier frequency to minimize the attenuation loss, because the attenuation loss increases with the carrier frequency. This scheme reduces the power consume to only $2 \mathrm{~mW}$ to transmit the image data at $2 \mathrm{Mbps}$ rate [55]. In order to achieve greater miniaturization of the antenna system, a high-frequency carrier is more suitable. This technique was pursued by Goa et al. to develop an ultrawideband $(3-5 \mathrm{GHz})$, low-power telemetry transceiver system that was designed with $0.18 \mu \mathrm{m}$ CMOS process within the outer dimension of $4 * 3 \mathrm{~mm}^{2}$. This system is able to transmit image data at the rate of $10 \mathrm{Mbps}$ with a $1.8 \mathrm{~V}$ power supply $[56,57]$. The same design was optimized by Diao et al., who increased the data rate to $15 \mathrm{Mbps}$ at $900 \mathrm{MHz}$ ISM band [58]. Kim et al. fabricated a high-speed, high-efficiency transceiver system using the $0.13 \mu \mathrm{m}$ CMOS process [59]. This chip used a simple on-off keying transmitter that could transmit the image data at a rate of $20 \mathrm{Mbps}$ using a $500 \mathrm{Mhz}$ $\mathrm{RF}$ channel. The entire chip occupied an area of only $1 \mathrm{~mm}^{2}$.

The compression of image data is an additional function of the chip that can increase the frame rate through the

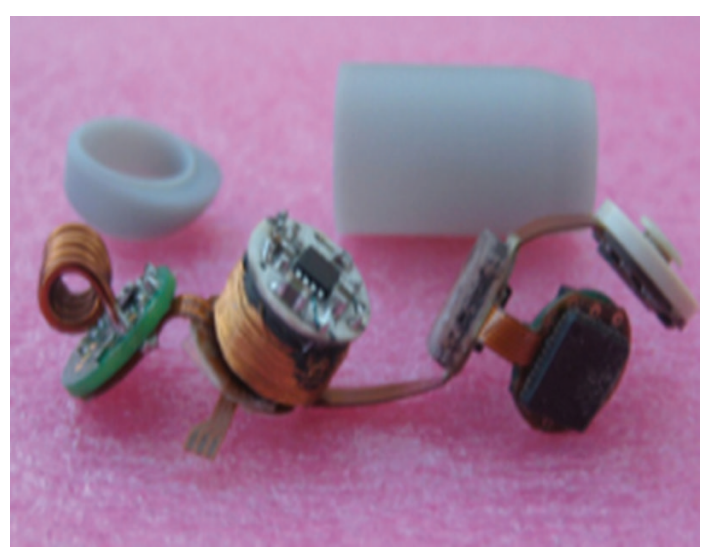

Figure 6: Prototype of an FPGA-based, miniaturized capsule [61].

low data rate transmission channel. Khan and Wahid proposed a low-power, low-complexity compressor for capsule endoscopy [60]. The compressor system is implemented using a $0.18 \mu \mathrm{m}$ CMOS process in $0.026 \mathrm{~mm}^{2}$ of silicon area, and it achieved an $80 \%$ compression ratio while consuming $42 \mu \mathrm{W}$ of power. The field-programmable gate array-based (FPGA-based) optimization of capsule design was proposed by Cavallotti et al. [61]. According to their prototype (Figure 6), it is possible to transmit a compressed image at the rate of $19 \mathrm{fps}$ over a $1.5 \mathrm{Mbps}$ channel. A low-power controlling and processing ASIC for capsule endoscopy was proposed by Chen et al. [62]. The ASIC was designed with a high-level miniaturization and power optimization technique that drew only $1.3 \mathrm{~mW}$ of power in active mode and zero standby current. Utilizing this ASIC capsule can save up to $45 \%$ of its battery power. Moreover, Xiao et al. proposed a novel, compressed-sensing imaging method [63]. This system compresses the data from the image during the capturing phase.

5.2. Capsule Actuation System. Actuation of the capsule is the most important issue, because significant improvements 
and advancements of capsule endoscopy technology are predicated on the development of a highly effective and highly efficient actuation system. Present capsules travel passively through the GI tract by natural peristaltic motion, which does not allow the doctor to control the motion of capsule or the orientation of the camera. The major problem is that doctors are unable to view according to their interest, which most likely is beyond the autonomous view of the capsule. In the open literature, vast categories of actuation mechanisms have been published concerning the control of the motion of the capsule. Some of more significant mechanisms are discussed below.

Shape memory alloys (SMAs) are kinds of alloys that can return to their previous shapes before their shapes were altered by temperature variations. Kim et al. used this principle and developed a pair of SMA springs. These springs, along with microhooks, were applied in endoscopic capsule locomotion and successfully tested in a pig's colon at the speed of $14.7 \mathrm{~mm} / \mathrm{min}$ for three surface contacts [64]. The same principle was used by Karagozler et al. to develop an SMA spring-based robot with adhesive type legs for crawling motion [65] (Figure 7(a)), but the bottleneck problem of the SMA-based system requires high power as well as very slow movement.

The four leg-based and eight leg-based locomotion mechanism was tested by Quirini et al. [66] (Figure 7(b)). One brushless DC motor was used to supply sufficient torque to the four leg-based system, while two motors were used in the eight leg-based prototype. During in vitro testing the eight leg-based prototype achieved a speed of $6 \mathrm{~cm} / \mathrm{min}$ with a two-degree of freedom (DOF) controlling option. A motor-based 12-leg capsule was proposed by Quaglia et al. [67] (Figure 7(c)) to increase the effectiveness of locomotion. A paddling-based, autonomous locomotion approach was introduced by Yang et al. [68] (Figure 7(d)), which attained an average speed of $28.4 \mathrm{~cm} / \mathrm{min}$ in tests on a live pig under anesthesia. One brushless DC motor with a diameter of $6 \mathrm{~mm}$ was used in this system to push the paddle forward.

A different concept using an anchoring mechanism for the capsule's propulsive force was proposed by Glass et al. [69] (Figure 7(e)). They simulated a mathematical model of a three-legged capsule and found that the system was able to generate a propulsive force greater than $0.27 \mathrm{~N}$.

In order to optimize the size and power consumption of the robotic capsule, some research groups have used an external mechanism combined with an internal mechanism based on magnetic theory. A capsule navigation system (Figure $7(\mathrm{~g})$ ) that used a three-dimensional, external magnetic field was developed by Olympus. The permanent magnet inside the capsule interacts with the external magnetic field and creates a rotating force due to the spiral body structure, allowing the capsule to be pushed forward or backward [70]. Likewise, Gao et al. proposed a selfpropelled capsule system with a magnetic sheet $(\varnothing 11 \mathrm{~mm}$ $\times ø 6 \mathrm{~mm} \times 10 \mathrm{~mm}$ ) attached to the capsule's outer body and external rectangular and cylindrical permanent magnets (80 $\mathrm{mm}$ and $90 \mathrm{~mm}$, resp.) [71] (Figure 7(f)). A hybrid locomotion system was introduced by Simi et al. that used an external permanent magnet to drag the capsule containing an internal, small, permanent magnet [72] (Figure 7(h)). Recently, a magnetically actuated, rolling, locomotion-based, soft capsule platform was proposed by Yim and Sitti [73] (Figure 7(i)) for diagnostic and therapeutic applications. The platform used two internal permanent magnets and a large, external magnet to deform the shape of the capsule and help to release a liquid drug from a $174 \mathrm{~mm}^{3}$ drug chamber.

Conversely, the concept of electrical stimulation of GI muscle excludes all of the bulky internal and external mechanical components for capsule actuation. Woo et al. [74] (Figure 8) proposed a mathematical model of an electrically propelled endoscopic capsule. The proposed model used double pairs of electrodes that had dimensions of $5 \times$ $6 \mathrm{~mm}^{2}$ for a $5 \mathrm{~ms}$ pulse (up to $9 \mathrm{~V}, 10-40 \mathrm{~Hz}$ ), which was able to move the capsule at a speed of $2.91 \mathrm{~mm} / \mathrm{s}$ in the forward direction and $2.23 \mathrm{~mm} / \mathrm{s}$ in the backward direction.

However, to date, several changed actuation mechanisms have been proposed for propelling the capsule and using some sophisticated option to control the capsule. So far, however, all of these mechanisms have been tested outside the human body due to concerns about the safety of the small bowel and smooth movement. Likewise, due to highpower consumption, these systems were tested using external power supplies. The major technical goal is the successful development and implementation of MEMS. Because all the present capsules are highly integrated and some of them are already hardly swallowable, making space for further tools within the ingestible dimensions is quite challenging. Then again, power is another issue of concern if the features are expanded and the performance is enhanced.

5.3. Miniaturized Power Source. Power is the most critical commodity for the successful development of capsule endoscopy technology, since most of the key characteristics that are required of the technology consume power. Thus, the development of a successful, fully functional capsule depends on the development of stronger, more reliable power sources. Today's capsules generally use two coin-shaped, silver-oxide batteries that can generate $20 \mathrm{~mW}$ of power. Other batteries, such as lithium ion polymer (LiPo) batteries, can generate more power, but only silver-oxide batteries have been approved for clinical use.

The alternative to the on-board battery system is WPT technology. RF System Lab was the first to utilize this technology successfully in their capsule systems named Norika and Sayaka, which do not have batteries [49]. The wireless powering system consists of two main parts to transmit power by the induction process, that is, a Helmholtz transmitting coil that must be worn by the patient and a three-dimensional, ferrite-core receiving coil with a rectification circuit [75] (Figure 9). The three-dimensional coil is put inside the capsule to ensure power is received efficiently irrespective of the orientation of the capsule. In recent years, there have been many publications in the literature on WPT technology for capsule endoscopy. An inductive power link for powering endoscopic capsules was introduced by Lenaerts and Puers transmitted $150 \mathrm{~mW}$ of power [76]. Similarly, power transmission systems were 


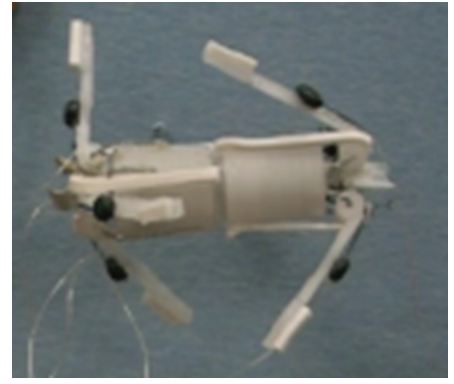

(a)

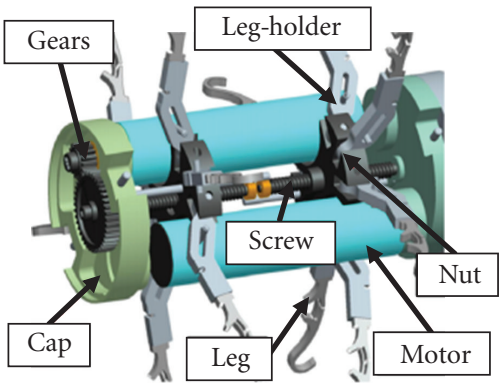

(c)

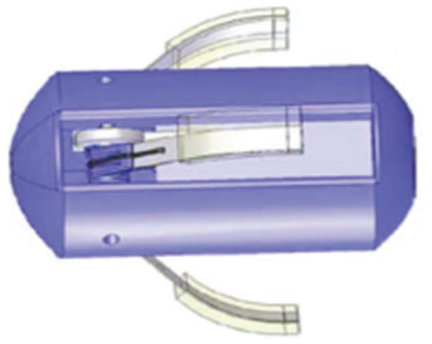

(e)

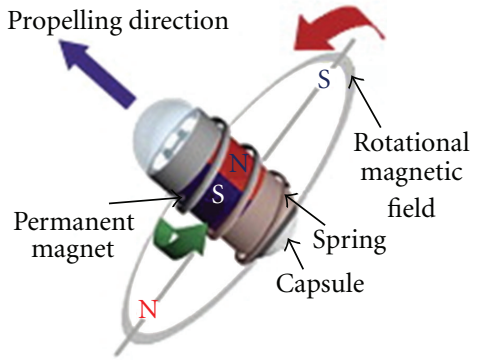

(g)

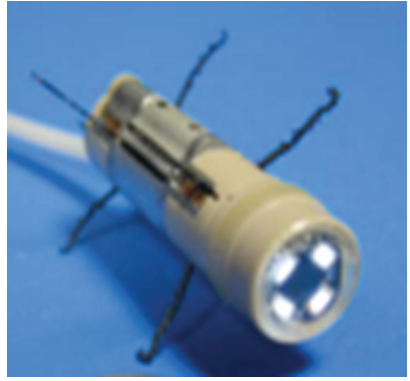

(b)

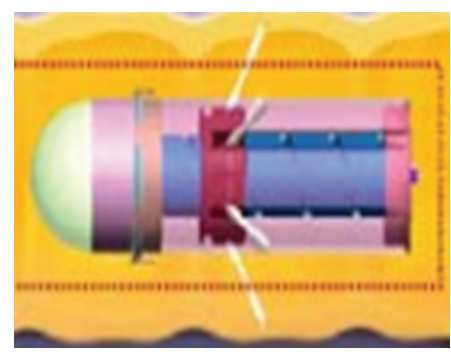

(d)

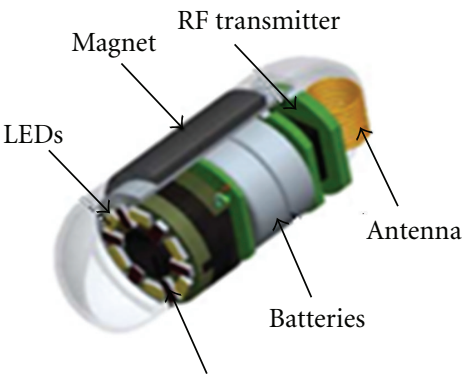

Image sensor

(f)

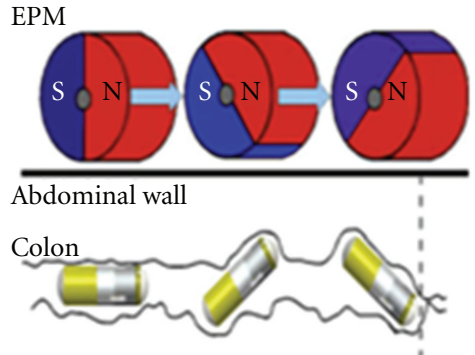

(h)

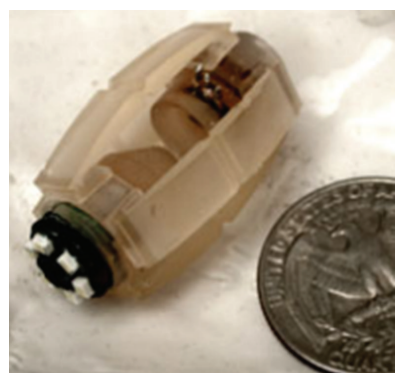

(i)

Figure 7: Capsule actuation mechanisms proposed by (a) Karagozler et al. [65], (b) Quirini et al. [66], (c) Quaglia et al. [67], (d) Yang et al. [68] (e) Glass et al. [69], (f) Gao et al. [71], (g) Olympus, Inc. [70], (h) Simi et al. [72], and (i) Yim and Sitti [73]. 

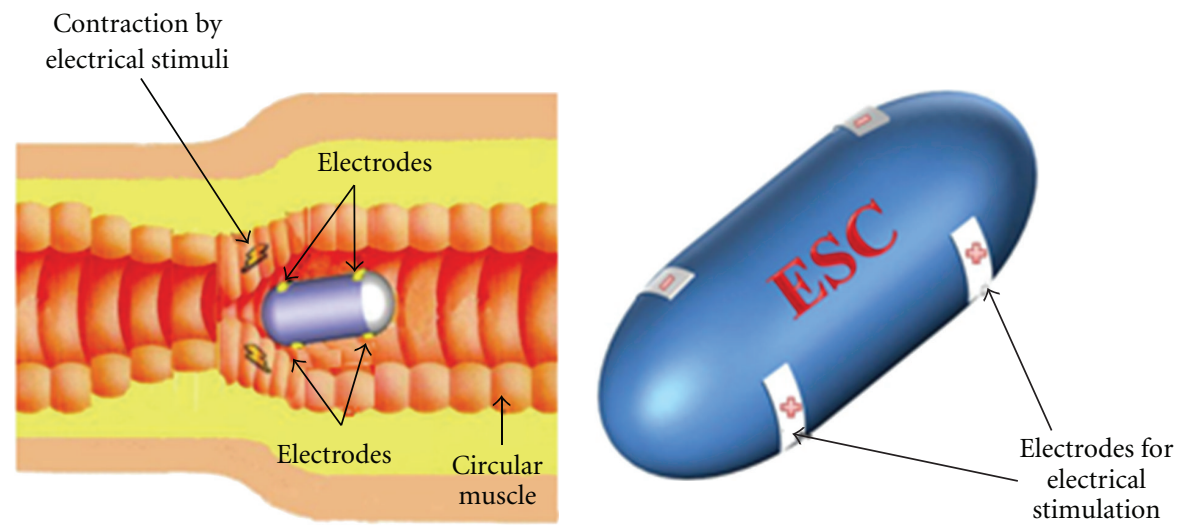

Figure 8: Capsule actuation by GI muscle stimulation [74].

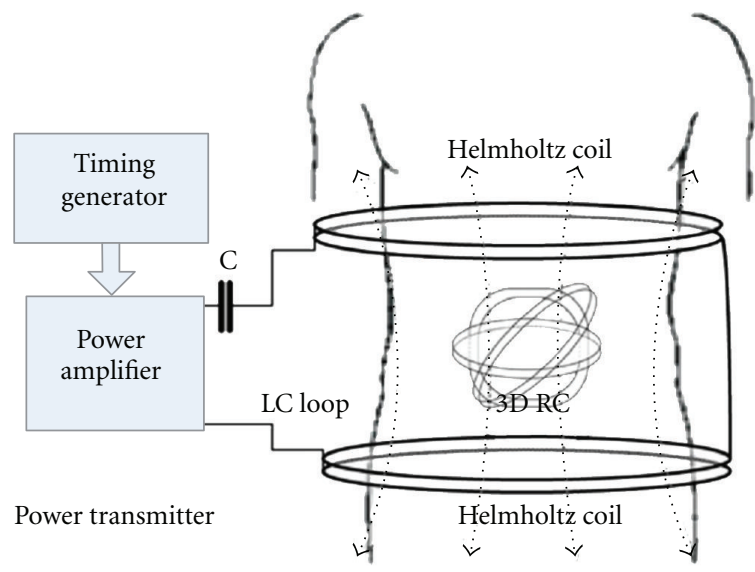

(a)

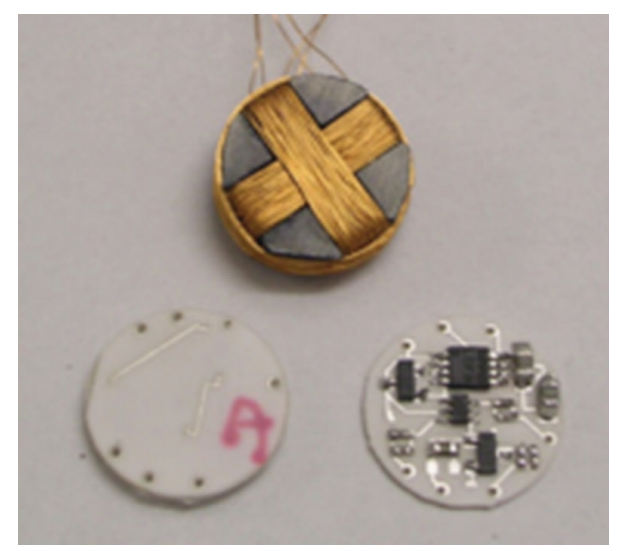

(b)

Figure 9: (a) Wireless power transmission system [75]; (b) 3D power receiving coil with rectifier circuit [77].

proposed by Carta et al. that provided $200 \mathrm{~mW}$ [77] and $330 \mathrm{~mW}$ [78] of power. In recent research, the efficiency of this technology has been improved tremendously, and Jia et al. reported the capability of transmitting $500 \mathrm{~mW}$ of power, which is more than adequate for an active capsule [79].

The most common problem with this technology is the variation of the coupling efficiency that occurs when the transmitting and receiving coils become misaligned due to the complex curvatures of the human GI tract. As hypothesized by Soma et al., there are mainly two kinds of misalignments, that is, lateral and angular [80]. Contrarily, the efficiency of the transmission system is related to frequency and intensity of the electromagnetic (EM) waves. A higher efficiency of the system increases the intensity of the EM signal and enhances the absorption of the EM signal by the body tissue, which creates a high risk for the body tissue. Very few safety studies of the WPT system have been reported in the literature. One such study, conducted by Xin et al. [81], found that the EM waves were safe for the human body when the resonant frequency is $266.5 \mathrm{kHz}$ at a transmitting power of $25 \mathrm{~W}$. However, additional safety studies are required before there can be extensive utilization of WPT technology.
Throughout the world, researchers are now attempting to develop miniaturized power sources for implantable medical devices (IMDs). Three-dimensional (3D), thin-layer microbattery $(\mathrm{MB})$ technology is the state of the art for geometrical energy and power density of battery technology. In $3 \mathrm{D} \mathrm{MB}$, the theoretically expected geometrical energy density is $20 \mathrm{mAh} / \mathrm{cm}^{2}$, which is 40 times greater than a twodimensional (2D) battery. In 2005, Nathan et al. developed a 3D, thin-film, Li-ion MB at Tel Aviv University in Israel [82]. This prototype battery had an energy density of $1 \mathrm{mAh} / \mathrm{cm}^{2}$, a cut-off voltage of $2.2 \mathrm{~V}$, and a footprint of $10 \mathrm{~mm}^{2}$. In 2008, in NASA's Jet Propulsion Laboratory, Whitacre and West also developed an MB for IMDs. This battery had extremely low volume $\left(\sim 1 \mathrm{~mm}^{3}\right)$ and was able to supply a total of $0.7 \mathrm{mAh}$ peek current [83]. Recently, the technology for the fabrication of the 3D battery structure has advanced remarkably [84], indicating that, in the near future, 3D MBs could become an excellent solution for the power requirements of next-generation capsules.

Another technology that is still progressing in the laboratory is harvesting energy from the human body. Piezoelectric nanogenerators can generate electrical energy from nanoscale mechanical energy. This can convert the 
body's mechanical energy, such as body motion, blood flow, muscle vibration, and breathing, to electrical energy for body centric devices.

\section{Discussion}

The endoscopic capsule has achieved little development in several areas, such as the capsule's lifetime, image resolution, and viewing angle, in individual medical products. But in order to efficiently identify diseases, high-quality images and longer capsule lifetimes are essential. In addition to capsule localization, the development of diagnosis and tissue manipulation tools associated with the capsule is still being pursued. In the open literature, many research groups have proposed diverse techniques for capsule localization. So far, none of them satisfies the two mandatory conditions, that is, the safety of GI muscle and an adequate, low-power supply that can maintain the capsule's activation until the examination of the entire GI tract has been completed. Due to the knotty structure of the human digestive tract, safety is a very important issue in the capsule's localization system. On the other hand, the present capsules are already highly integrated, and there is inadequate space available to install additional actuation mechanisms.

Thus, this paper is focused on two different steps that could lead to the successful development of next-generation capsules that can possess active motion-controlling systems and that can accommodate some additional, advanced features, that is, (1) the development of mixed-mode, multifunctional ASIC with the latest CMOS technology and (2) the design of an MEMS/NEMS-based microactuation system.

Recently, the CMOS technology has experienced extensive, exponential miniaturization of the size of its transistors. Table 2 shows the progress in the development of miniaturization technology. Recently, the Taiwan Semiconductor Manufacturing Company (TSMC) introducing its $28 \mathrm{~nm}$ process in 2011 [85]. The $28 \mathrm{~nm}$ technology uses high-K metal that increases the gate density by a factor of two and decreases the area of the chip by $50 \%$ [69]. In this technology, the chip can operate at very low power $(0.6 \mathrm{~V})$ in high-power efficiency mode [86]. The OCA and antennain-package $(\mathrm{AiP})$ are smart technologies that provide the single-chip radio solution. These technologies allow the codesign of the antenna and the radio chip (in micro/nano CMOS technology) into the same high-sensitivity silicon substrate package, which compresses the die area of the radio system [87-92]. There is a tradeoff between antenna size and performance in terms of operating frequency, that is, the higher (lower) the frequency, the smaller (larger) the size can be. Because of this complexity, the OCA is easier to incorporate in radio systems that have frequencies of $60 \mathrm{GHz}$ or greater. Recently, ISM band OCAs have been designed and tested by several research groups. Okabe et al. proposed a $2.3 \times 2 \mathrm{~mm}$, silicon-based OCA in [92], and Mohammadpour-Aghdam et al. proposed $3 \times 1.5 \mathrm{~mm}$, miniaturized, integrated antennas in three different ISM bands $(900 \mathrm{MHz}, 2.4 \mathrm{GHz}$, and $5.8 \mathrm{GHz})$ in [88].
TABLE 2: Development of miniaturization technology.

\begin{tabular}{lc}
\hline CMOS process & Year introduced \\
\hline $180 \mathrm{~nm}$ process & 2001 \\
$130 \mathrm{~nm}$ process & 2003 \\
$90 \mathrm{~nm}$ process & 2004 \\
$65 \mathrm{~nm}$ process & 2006 \\
$40 \mathrm{~nm}$ process & 2008 \\
$28 \mathrm{~nm}$ process & 2011 \\
$20 \mathrm{~nm}$ process & Under processing \\
\hline
\end{tabular}

Many research groups are working on optimization of chips for the capsule system. The best outcomes for the different functional chips are listed in Table 3. From the table, all the research carried out for the individual function of capsule and with earlier developed CMOS technology. Clearly, there is a big opportunity to further optimize the whole capsule designing with latest CMOS technology. Therefore, developing the mixed-mode, multifunctional chip (image sensor, image compressor, transceiver, and antenna in a single chip) with the latest CMOS process can be the greatest development. Figure 10 shows the modified architecture of the mixed-mode chip (modified from Chen et al.'s architecture [62]). The realization of such a design can condense the size of present capsules and create free space for an enhanced actuation system. In addition, the capsule's power consumption can be reduced.

Capsule actuation is still the first and most significant technical challenge standing on the way of the successful development and deployment of medical robots or robotic endoscopic capsules. Among all of the capsule actuation systems proposed by different research groups, the electrical stimulation of GI muscles is one that excludes all of the on-board mechanical components. But in terms of power consumption, the external magnetic actuation system has less power demand. A hybrid capsule actuation system with the combination of electric stimulation and external magnetic actuation could result in a viable solution to the capsule actuation issue. Conversely, the concept of an active medical robot is not only limited by the locomotion concerns associated with endoscopic capsules; it also is a major concern in other applications, including microsurgery, drug delivery, microgrippers, and microsyringes. So the development of MEMS/NEM-based active medical robots must consider these areas of concern in addition to endoscopic capsule localization. This perception is already being addressed by some research projects. One such project is the Vector project funded by the European Commission, which aims to develop an intelligent, endoscopic capsule with micronanotechnology. The Vector project already has developed a capsule that is able to detect blood inside the bowel, and the researchers are still considering and developing the suitable design.

\section{Conclusions}

Over the past decade, WCE has become the sole technology for the direct diagnosis of GI diseases because it is 
TABLE 3: The best research outcome in capsule device optimization.

\begin{tabular}{|c|c|c|c|c|c|}
\hline Reference & Chip & Outcome & Tech. & Die area & Power \\
\hline [59] & Transceiver & $20 \mathrm{Mbps}$ & $0.13 \mathrm{um}$ & $1 \mathrm{~mm}^{2}$ & $0.7-22 \mathrm{~mW}$ \\
\hline$[60]$ & Image Comp. & $80 \%$ & $0.18 \mathrm{um}$ & $0.026 \mathrm{~mm}^{2}$ & $42 \mu \mathrm{W}$ \\
\hline [93] & Image sensor & $2 \mathrm{fps}$ & $0.18 \mathrm{um}$ & $6.4 \mathrm{~mm}^{2}$ & $2.2 \mathrm{~mW}$ \\
\hline$[88]$ & On-chip antenna & -28.2 (gain) & $0.18 \mathrm{um}$ & $4.5 \mathrm{~mm}^{2}$ & NA \\
\hline
\end{tabular}

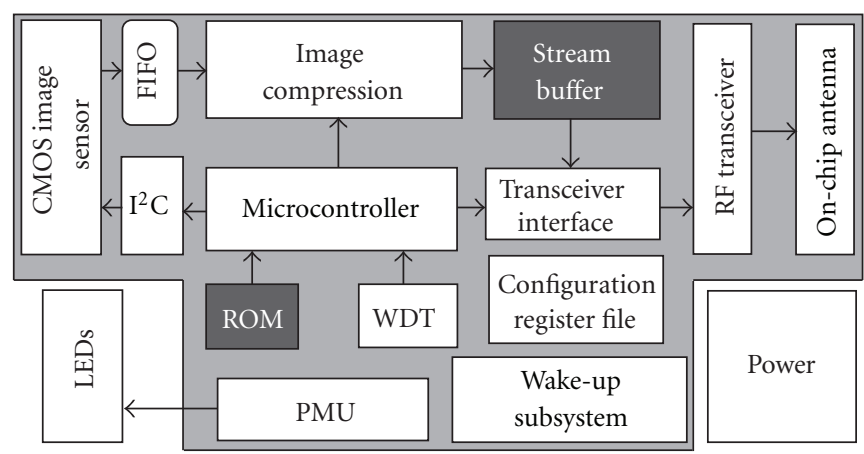

FIGURE 10: Architecture of mixed-mode, multi-functional ASIC ([62] modified).

painless, noninvasive, and effective. The development of CMOS miniaturization technology made the development of a swallowable video capsule possible. To expand its applicability, the quality of medical images, frame rate, and the lifetime of the capsule must be improved. All of these inadequacies are the result of power supply limitations. Therefore, optimization of the available power in mixedmode, multifunctional ASIC has the potential for providing a viable solution for the present limitations.

The development of the mixed-mode multifunction, ASIC, combined with an image sensor, processing unit, transceiver, and antenna, provides a viable approach for compressing the size of present capsules, which is a compulsory requirement for the development of an active medical robot. In the next-generation, active, medical robot, actuation, microsurgery, biopsy, and drug delivery are the most exciting features of the capsule. The development of a MEMS-based actuation system shows promise for allowing the current prototype of an active medical robot to become a viable, functional tool for the diagnosis of diseases of the human GI tract in the future.

\section{Acknowledgment}

Authors are deeply grateful to the Ministry of Higher Education, Malaysia, for providing financial support for this research work under the grant FRGS/FASA/TAHUN/SKK/ JPP/03/6 via Politeknik Tuanku Syed Sirajuddin.

\section{References}

[1] G. Iddan, G. Meron, A. Glukhovsky, and P. Swain, "Wireless capsule endoscopy," Nature, vol. 405, no. 6785, pp. 417-418, 2000.
[2] G. G. Ginsberg, A. N. Barkun, J. J. Bosco et al., "Wireless capsule endoscopy," Gastrointestinal Endoscopy, vol. 56, no. 5, pp. 621-624, 2002.

[3] S. J. Spaner and G. L. Warnock, "A brief history of endoscopy, laparoscopy, and laparoscopic surgery," Journal of Laparoendoscopic and Advanced Surgical Techniques Part A, vol. 7, no. 6, pp. 369-373, 1997.

[4] W. Y. Lau, C. K. Leow, and A. K. C. Li, "History of endoscopic and laparoscopic surgery," World Journal of Surgery, vol. 21, no. 4, pp. 444-453, 1997.

[5] P. M. Trivedi and P. R. S. Thomas, "Principles of rigid endoscopy," Surgery, vol. 29, no. 2, pp. 85-88, 2011.

[6] K. Schwab and S. Singh, "An introduction to flexible endoscopy," Surgery, vol. 29, no. 2, pp. 80-84, 2011.

[7] L. Morgenstern, "Fiberoptic endoscopy is 50! Basil I. Hirschowitz, MD,” Surgical Innovation, vol. 13, no. 3, pp. 165167, 2006.

[8] J. A. DiSario, B. T. Petersen, W. M. Tierney et al., "Enteroscopes," Gastrointestinal Endoscopy, vol. 66, no. 5, pp. 872-880, 2007.

[9] J. D. Waye, "Enterscopy," Gastrointestinal Endoscopy, vol. 46, no. 3, pp. 247-256, 1997.

[10] B. W. Watson, B. Ross, and A. W. Kay, "Telemetering from within the body using a pressure-sensitive radio pill," Gut, vol. 3, pp. 181-186, 1962.

[11] B. Jacobson and L. Nordberg, "Endoradiosondes for pressure telemetering," IRE transactions on Bio-Medical Electronics, vol. 8, pp. 192-196, 1961.

[12] G. X. Zhou, "Swallowable or implantable body temperature telemeter-body temperature radio pill," in Proceedings of the 15th Annual Northeast Bioengineering Conference, pp. 165166, March 1989.

[13] A. Uchiyama, "Endoradiosonde needs micro machine technology," in Proceedings of the 6th International Symposium on Micro Machine and Human Science, pp. 31-37, October 1995. 
[14] “The Heidelberg pH diagnostic system," http://www.phcapsule.com/prodinfo.htm.

[15] S. Maqbool, H. P. Parkman, and F. K. Friedenberg, "Wireless capsule motility: comparison of the smartPill GI monitoring system with scintigraphy for measuring whole gut transit," Digestive Diseases and Sciences, vol. 54, no. 10, pp. 2167-2174, 2009.

[16] C. P. Swain, F. Gong, and T. N. Mills, "Wireless transmission of a colour television moving image from the stomach using a miniature ccd camera, light source and microwave transmitter," Gastrointestinal Endoscopy, vol. 45, no. 4, p. AB40, 1997.

[17] G. J. Iddan and C. P. Swain, "History and development of capsule endoscopy," Gastrointestinal Endoscopy Clinics of North America, vol. 14, no. 1, pp. 1-9, 2004.

[18] "Human digestive," http://www.medical-reference.net/2012/ 07/digestive-system-digestive-system-is.html.

[19] L. T. Weaver, S. Austin, and T. J. Cole, "Small intestinal length: a factor essential for gut adaptation," Gut, vol. 32, no. 11, pp. 1321-1323, 1991.

[20] B. M. Underhill, "Intestinal length in man," British Medical Journal, vol. 2, no. 4950, pp. 1243-1246, 1955.

[21] B. S. Lewis, "The history of enteroscopy," Gastrointestinal Endoscopy Clinics of North America, vol. 9, no. 1, pp. 1-11, 1999.

[22] D. G. Adler and C. J. Gostout, "Wireless capsule endoscopy," Hospital Physician, pp. 14-22, 2003.

[23] G. D. Meron, "The development of the swallowable video capsule (M2A)," Gastrointestinal Endoscopy, vol. 52, no. 6, pp. 817-819, 2000.

[24] C. Mc Caffrey, O. Chevalerias, C. O'Mathuna, and K. Twomey, "Swallowable-capsule technology," IEEE Pervasive Computing, vol. 7, no. 1, pp. 23-29, 2008.

[25] M. Yu, “M2A capsule endoscopy," Gastroenterology Nursing, vol. 25, pp. 24-27, 2001.

[26] "OMOM capsule," http://english..jinshangroup.com/contents/1091/1348.html.

[27] R. Eliakim, K. Yassin, I. Shlomi, A. Suissa, and G. M. Eisen, "A novel diagnostic tool for detecting oesophageal pathology: the PillCam oesophageal video capsule," Alimentary Pharmacology and Therapeutics, vol. 20, no. 10, pp. 1083-1089, 2004.

[28] C. Y. Li, B. L. Zhang, C. X. Chen, and Y. M. Li, "OMOM capsule endoscopy in diagnosis of small bowel disease," Journal of Zhejiang University: Science B, vol. 9, no. 11, pp. 857862, 2008.

[29] B. S. Lewis, "The utility of capsule endoscopy in obscure gastrointestinal bleeding," Techniques in Gastrointestinal Endoscopy, vol. 5, no. 3, pp. 115-120, 2003.

[30] “Given imaging," http://www.givenimaging.com/en-us/Pages/ Legal-Notice.aspx.

[31] Given Imaging company, http://www.givenimaging.com/.

[32] D. S. Mishkin, R. Chuttani, J. Croffie et al., "ASGE technology status evaluation report: wireless capsule endoscopy," Gastrointestinal Endoscopy, vol. 63, no. 4, pp. 539-545, 2006.

[33] Y. C. Metzger, S. N. Adler, A. B. G. Shitrit, B. Koslowsky, and I. Bjarnason, "Comparison of a new PillCam SB2 video capsule versus the standard PillCam SB for detection of small bowel disease," Reports in Medical Imaging, vol. 2, pp. 7-11, 2009.

[34] "PillCam SB 2-Ex," http://medgadget.com/2010/10/given imaging_announces_new_pillcam_offerings.html.
[35] G. M. Eisen, "Pillcam ESO: a primer," Techniques in Gastrointestinal Endoscopy, vol. 8, no. 4, pp. 154-159, 2006.

[36] B. Koslowsky, H. Jacob, R. Eliakim, and S. N. Adler, "PillCam ESO in esophageal studies: improved diagnostic yield of 14 frames per second (fps) compared with $4 \mathrm{fps,"} \mathrm{Endoscopy,} \mathrm{vol.}$ 38, no. 1, pp. 27-30, 2006.

[37] I. M. Gralnek, S. N. Adler, K. Yassin, B. Koslowsky, Y. Metzger, and R. Eliakim, "Detecting esophageal disease with second-generation capsule endoscopy: initial evaluation of the PillCam ESO 2," Endoscopy, vol. 40, no. 4, pp. 275-279, 2008.

[38] D. G. Adler, B. Chand, J. D. Conway et al., "Capsule endoscopy of the colon," Gastrointestinal Endoscopy, vol. 68, no. 4, pp. 621-623, 2008.

[39] Z. Fireman and Y. Kopelman, "The colon-the latest terrain for capsule endoscopy," Digestive and Liver Disease, vol. 39, no. 10, pp. 895-899, 2007.

[40] C. Spada, C. Hassan, M. Munoz-Navas et al., "Secondgeneration colon capsule endoscopy compared with colonoscopy," Gastrointestinal Endoscopy, vol. 74, no. 3, pp. 581-591, 2011.

[41] P. N. Figueiredo, I. N. Figueiredo, S. Prasath, and R. Tsai, "Automatic polyp detectionin Pillcam Colon 2 capsule images and videos: preliminary feasibility report," Diagnostic and Therapeutic Endoscopy, pp. 1-7, 2011.

[42] S. N. Adler and Y. C. Metzger, "PillCam COLON capsule endoscopy: recent advances and new insights," Therapeutic Advances in Gastroenterology, vol. 4, no. 4, pp. 265-268, 2011.

[43] Z. Liao, R. Gao, F. Li et al., "Fields of applications, diagnostic yields and findings of OMOM capsule endoscopy in 2400 Chinese patients," World Journal of Gastroenterology, vol. 16, no. 21, pp. 2669-2676, 2010.

[44] "Olympus capsule," http://www.european-hospital.com/en/ article/7244-Video_Capsule_Endoscopy.html.

[45] C. Gheorghe, R. Iacob, and I. Bancila, "Olympus capsule endoscopy for small bowel examination," Journal of Gastrointestinal and Liver Diseases, vol. 16, no. 3, pp. 309-313, 2007.

[46] D. R. Cave, D. E. Fleischer, J. A. Leighton et al., "A multicenter randomized comparison of the Endocapsule and the Pillcam SB," Gastrointestinal Endoscopy, vol. 68, no. 3, pp. 487-494, 2008.

[47] "Brochure of MiroCam capsule," http://www.synmed.co.uk/ news_mirocam.htm.

[48] H. M. Kim, Y. J. Kim, H. J. Kim et al., "A pilot study of sequential capsule endoscopy using MiroCam and PillCam SB devices with different transmission technologies," Gut and Liver, vol. 4, no. 2, pp. 192-200, 2010.

[49] "Sayaka capsule system," http://www.rfsystemlab.com/en/ sayaka/index.html.

[50] T. S. Kim, J. O. Park, S. W. Moon, B. K. Kim, J. Y. Kang, and J. Han, "Method and apparatus for communication between inside and outside of transmission medium using transmission medium as communication line," US Patent Document, 2007.

[51] K. R. Canlas, B. M. Dobozi, S. Lin et al., "Using capsule endoscopy to identify GI tract lesions in cirrhotic patients with portal hypertension and chronic anemia," Journal of Clinical Gastroenterology, vol. 42, no. 7, pp. 844-848, 2008.

[52] G. C. Sturniolo, V. Di Leo, M. G. Vettorato et al., "Small bowel exploration by wireless capsule endoscopy: results from 314 procedures," American Journal of Medicine, vol. 119, no. 4, pp. 341-347, 2006.

[53] A. K. Hara, J. A. Leighton, V. K. Sharma, R. I. Heigh, and D. E. Fleischer, "Imaging of small bowel disease: comparison of 
capsule endoscopy, standard endoscopy, barium examination, and CT," Radiographics, vol. 25, no. 3, pp. 697-711, 2005.

[54] E. Rondonotti, J. M. Herrerias, M. Pennazio, A. Caunedo, M. Mascarenhas-Saraiva, and R. De Franchis, "Complications, limitations, and failures of capsule endoscopy: a review of 733 cases," Gastrointestinal Endoscopy, vol. 62, no. 5, pp. 712-716, 2005.

[55] J. Thoné, S. Radiom, D. Turgis, R. Carta, G. Gielen, and R. Puers, "Design of a 2 Mbps FSK near-field transmitter for wireless capsule endoscopy," Sensors and Actuators A, vol. 156, no. 1, pp. 43-48, 2009.

[56] Y. Gao, Y. Zheng, S. Diao et al., "Low-power ultrawideband wireless telemetry transceiver for medical sensor applications," IEEE Transactions on Biomedical Engineering, vol. 58, no. 3, pp. 768-772, 2011.

[57] Y. Gao, S. Diao, C. W. Ang, Y. Zheng, and X. Yuan, "Low power ultra-wideband wireless telemetry system for capsule endoscopy application," in Proceedings of IEEE International Conference on Robotics, Automation and Mechatronics (RAM '10), pp. 96-99, sgp, June 2010.

[58] S. Diao, Y. Gao, W. Toh et al., "A low-power, high data-rate CMOS ASK transmitter for wireless capsule endoscopy," in Defense Science Research Conference and Expo, pp. 1-4.

[59] K. Kim, S. Yun, S. Lee, S. Nam, Y. Yoon, and C. Cheon, "A design of a high-speed and high-efficiency capsule endoscopy system," IEEE Transactions on Biomedical Engineering, vol. 59, pp. 1005-1011, 2012.

[60] T. H. Khan and K. A. Wahid, "Low power and low complexity compressor for video capsule endoscopy," IEEE Transactions on Circuits and Systems For Video Technology, vol. 21, pp. 1534-1546, 2011.

[61] C. Cavallotti, P. Merlino, M. Vatteroni et al., "An FPGA-based versatile development system for endoscopic capsule design optimization," Sensors and Actuators A, vol. 172, no. 1, pp. 301-307, 2011.

[62] X. Chen, X. Zhang, L. Zhang et al., "A wireless capsule endoscope system with low-power controlling and processing ASIC," IEEE Transactions on Biomedical Circuits and Systems, vol. 3, no. 1, pp. 11-22, 2009.

[63] L. Xiao, K. Liu, and D. P. Han, "CMOS low data rate imaging method based on compressed sensing," Optics \& Laser Technology, vol. 44, pp. 1338-1345, 2012.

[64] B. Kim, S. Lee, J. H. Park, and J. O. Park, "Design and fabrication of a locomotive mechanism for capsule-type endoscopes using shape memory alloys (SMAs)," IEEE/ASME Transactions on Mechatronics, vol. 10, no. 1, pp. 77-86, 2005.

[65] M. E. Karagozler, E. Cheung, J. Kwon, and M. Sitti, "Miniature endoscopie capsule robot using biomimetic micro-patterned adhesives," in Proceedings of the 1st IEEE/RAS-EMBS International Conference on Biomedical Robotics and Biomechatronics (BioRob '06), pp. 105-111, February 2006.

[66] M. Quirini, S. Scapellato, P. Valdastri, A. Menciassi, and P. Dario, "An approach to capsular endoscopy with active motion," in Proceedings of the 29th Annual International Conference of IEEE-EMBS, Engineering in Medicine and Biology Society (EMBC'07), pp. 2827-2830, August 2007.

[67] C. Quaglia, E. Buselli, R. J. Webster III, P. Valdastri, A. Menciassi, and P. Dario, "An endoscopic capsule robot: a meso-scale engineering case study," Journal of Micromechanics and Microengineering, vol. 19, no. 10, Article ID 105007, 2009.

[68] S. Yang, K. Park, J. Kim, T. S. Kim, I. J. Cho, and E. S. Yoon, "Autonomous locomotion of capsule endoscope in gastrointestinal," in Proceedings of the 33rd Annual International Conference of the IEEE EMBS, pp. 6659-6663, 2011.
[69] P. Glass, E. Cheung, and M. Sitti, "A legged anchoring mechanism for capsule endoscopes using micropatterned adhesives," IEEE Transactions on Biomedical Engineering, vol. 55, pp. 2759-2767, 2008.

[70] Y. Kusuda, "A further step beyond wireless capsule endoscopy," Sensor Review, vol. 25, no. 4, pp. 259-260, 2005.

[71] M. Gao, C. Hu, Z. Chen, H. Zhang, and S. Liu, "Design and fabrication of a magnetic propulsion system for self-propelled capsule endoscope," IEEE Transactions on Biomedical Engineering, vol. 57, no. 12, pp. 2891-2902, 2010.

[72] M. Simi, P. Valdastri, C. Quaglia, A. Menciassi, and P. Dario, "Design, fabrication, and testing of a capsule with hybrid locomotion for gastrointestinal tract exploration," IEEE/ASME Transactions on Mechatronics, vol. 15, no. 2, pp. 170-180, 2010.

[73] S. Yim and M. Sitti, "Design and rolling locomotion of a magnetically actuated soft capsule endoscope," IEEE Transactions on Robotics, vol. 28, pp. 183-194, 2012.

[74] S. H. Woo, T. W. Kim, Z. Mohy-Ud-Din, I. Y. Park, and J. H. Cho, "Small intestinal model for electrically propelled capsule endoscopy," BioMedical Engineering OnLine, vol. 10, 2011.

[75] G. Pan, W. Xin, G. Yan, and J. Chen, "A video wireless capsule endoscopy system powered wirelessly: design, analysis and experiment," Measurement Science and Technology, vol. 22, no. 6, Article ID 065802, pp. 1-9, 2011.

[76] B. Lenaerts and R. Puers, "An inductive power link for a wireless endoscope," Biosensors and Bioelectronics, vol. 22, no. 7, pp. 1390-1395, 2007.

[77] R. Carta, G. Tortora, J. Thoné et al., "Wireless powering for a self-propelled and steerable endoscopic capsule for stomach inspection," Biosensors and Bioelectronics, vol. 25, no. 4, pp. 845-851, 2009.

[78] R. Carta, J. Thoné, and R. Puers, "A wireless power supply system for robotic capsular endoscopes," Sensors and Actuators A, vol. 162, no. 2, pp. 177-183, 2010.

[79] Z. Jia, G. Yan, H. Liu, Z. Wang, P. Jiang, and Y. Shi, “The optimization of wireless power transmission: design and realization," The International Journal of Medical Robotics and Computer Assisted Surgery, vol. 8, 2012, (abstract).

[80] M. Soma, D. C. Galbraith, and R. L. White, "Radio frequency coils in implantable devices: misalignment analysis and design procedure," IEEE Transactions on Biomedical Engineering, vol. 34, no. 4, pp. 276-282, 1987.

[81] W. H. Xin, G. Z. Yan, and W. X. Wang, "Study on human safety in wireless power transmission system for capsule endoscopy," Chinese Journal of Biomedical Engineering, vol. 28, no. 5, pp. 719-724, 2009.

[82] M. Nathan, D. Golodnitsky, V. Yufit et al., "Three-dimensional thin-film Li-ion microbatteries for autonomous MEMS," Journal of Microelectromechanical Systems, vol. 14, no. 5, pp. 879-885, 2005.

[83] J. Whitacre and W. West, "Integrated microbatteries for implantable medical devices," NASA Tech Briefs, 2008.

[84] M. Roberts, P. Johns, J. Owen et al., " $3 \mathrm{D}$ lithium ion batteries-from fundamentals to fabrication," Journal of Materials Chemistry, vol. 21, no. 27, pp. 9876-9890, 2011.

[85] "CMOS process," http://www.st.com/internet/com/press_ release/t3173.jsp.

[86] N. Ickes, G. Gammie, M. E. Sinangil, R. Rithe, J. Gu, A. Wang et al., "A $28 \mathrm{~nm} 0.6 \mathrm{~V}$ low power DSP for mobile applications," IEEE Journal of Solid-State Circuits, vol. 47, pp. 35-46, 2012.

[87] Y. P. Zhang, "Antenna-in-package technology for modern radio systems," in Proceedings of IEEE International Workshop on Antenna Technology (IWAT '06), pp. 37-40, March 2006. 
[88] K. Mohammadpour-Aghdam, S. Radiom, Z. Faraji-Dana, G. A. E. Vandenbosch, and G. G. E. Gielen, "Miniaturized integrated antennas for far-field wireless powering," International Journal of Electronics and Communications, vol. 66, no. 10, pp. 789-7796, 2012.

[89] S. Pan, L. Gilreath, P. Heydari, and F. Capolino, "Designs of fully on-chip antennas in (Bi)CMOS technology," in Proceedings of IEEE International Workshop on Antenna Technology, pp. 343-346, 2012.

[90] Y. P. Zhang and D. Liu, "Antenna-on-chip and antenna-inpackage solutions to highly integrated millimeter-wave devices for wireless communications," IEEE Transactions on Antennas and Propagation, vol. 57, no. 10, pp. 2830-2841, 2009.

[91] S. Radiom, M. Baghaei-Nejad, G. Vandenbosch, L. R. Zheng, and G. Gielen, "Far-field RF powering system for RFID and implantable devices with monolithically integrated on-chip antenna," in Proceedings of IEEE Radio Frequency Integrated Circuits Symposium (RFIC'10), pp. 113-116, May 2010.

[92] K. Okabe, W. Lee, Y. Harada, and M. Ishida, "Silicon based onchip antenna using an LC resonator for near-field RF systems," Solid-State Electronics, vol. 67, pp. 100-104, 2011.

[93] M. Zhang, A. Bermak, X. Li, and Z. Wang, "A low power CMOS image sensor design for wireless endoscopy capsule," in Proceedings of IEEE-BIOCAS Biomedical Circuits and Systems Conference (BIOCAS '08), pp. 397-400, November 2008. 

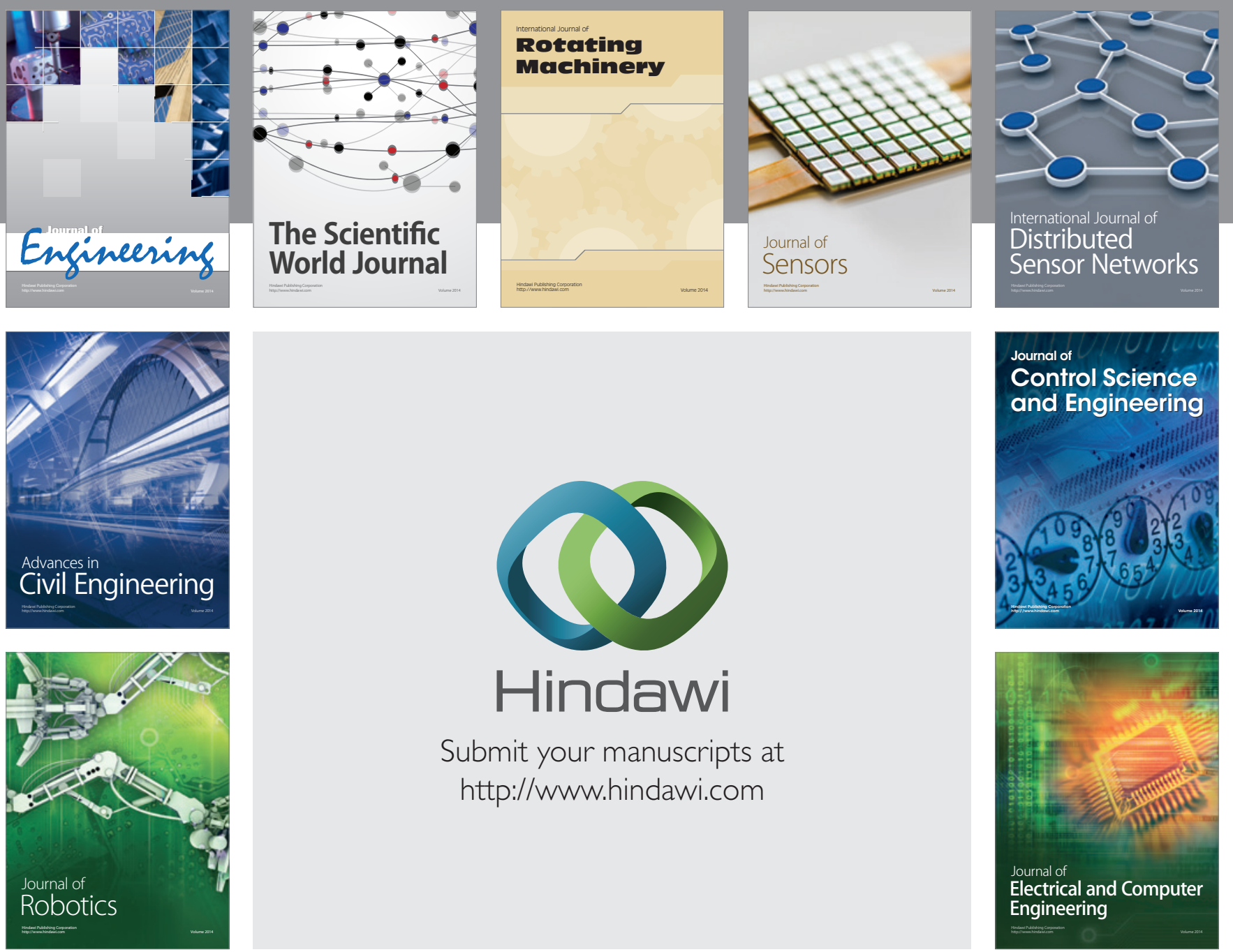

Submit your manuscripts at

http://www.hindawi.com
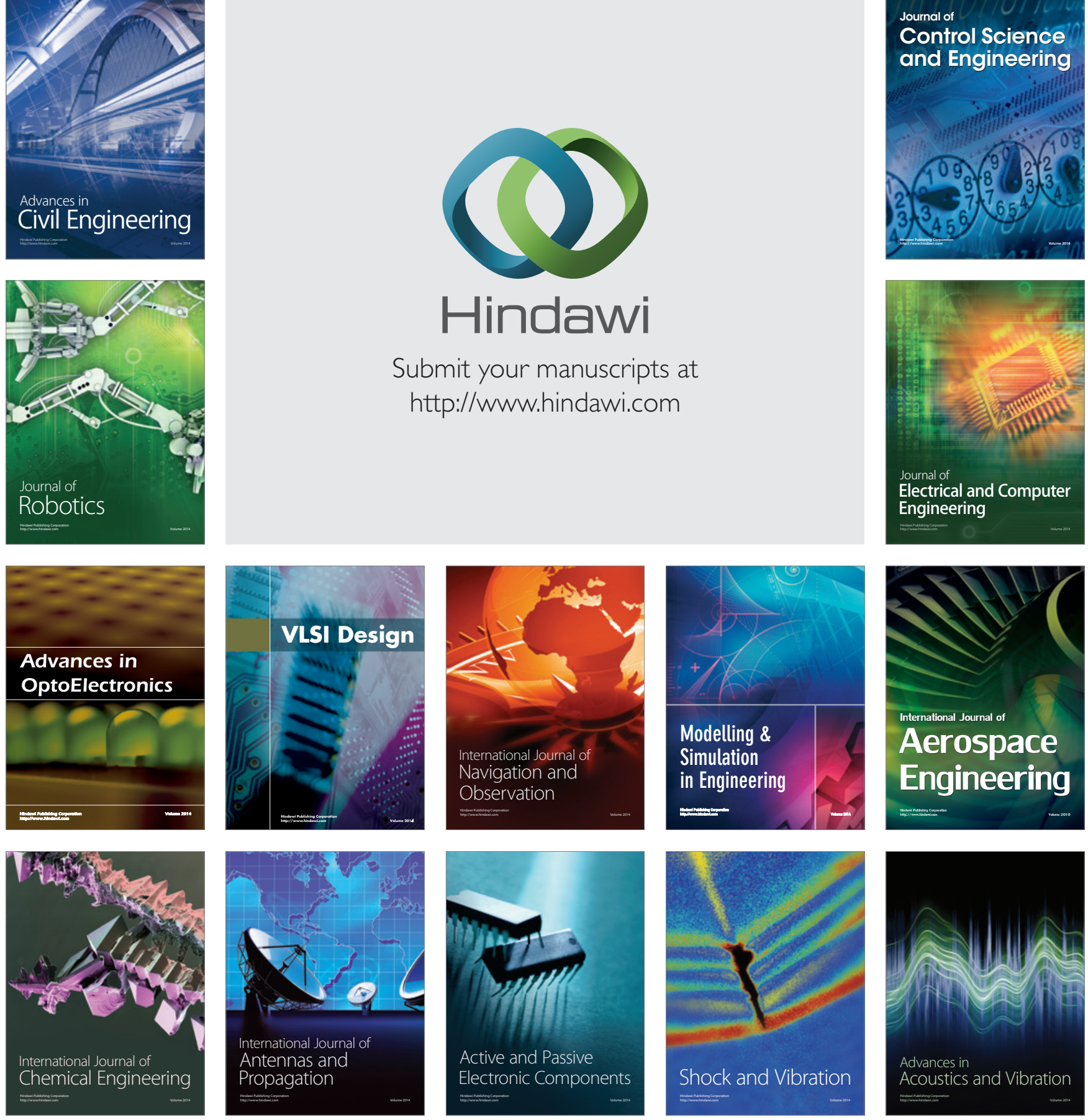